\title{
Deposition of Carbon Particulates Surfaces on Zeolites by Electron-Beam Evaporation of Graphite
}

\author{
Andrew Morgan, Joseph Corrao, Marcia R. Silva* \\ Water Technology Accelerator (WaTA), University of Wisconsin-Milwaukee, Milwaukee, Wisconsin, USA \\ Email: *msilva@uwm.edu
}

How to cite this paper: Morgan, A., Corrao, J. and Silva, M.R. (2022) Deposition of Carbon Particulates Surfaces on Zeolites by Electron-Beam Evaporation of Graphite. Materials Sciences and Applications, 13, 78-90.

https://doi.org/10.4236/msa.2022.132006

Received: January 14, 2022

Accepted: February 21, 2022

Published: February 24, 2022

Copyright $\odot 2022$ by author(s) and Scientific Research Publishing Inc. This work is licensed under the Creative Commons Attribution International License (CC BY 4.0).

http://creativecommons.org/licenses/by/4.0/

(c) (i) Open Access

\begin{abstract}
Disordered carbon particulates were deposited on the surface of natural acid treated zeolite through graphite evaporation by electron beam to improve adsorption properties of the porous material. This study focuses on the development of the new material and not on applications. The effect of acid treatment and carbon deposition on the physical properties of the natural material was investigated. The zeolites were characterized via spectroscopic and microscopic methods, thermal analysis, and gas sorption analysis. Analysis revealed that the surface area and volume increased by a factor of ten after the carbon-coating was deposited onto the zeolite surface and indicated that the $\mathrm{Si} / \mathrm{Al}$ ratio was higher with the acid treated sample. The acid treatment promoted dealumination of the zeolite and increased overall surface area, whereas the carbon coating re-aluminated the zeolite while adding silica back to the main molecular framework, thus increasing crystallinity and thermal stability and further improving the high surface area produced by the acid treatment.
\end{abstract}

\section{Keywords}

Zeolite, E-Beam Evaporation, Graphite, Adsorption, Acid Treatment

\section{Introduction}

Zeolites are hydrated aluminosilicate minerals which possess structurally interlinked tetrahedra of alumina $\left(\mathrm{AlO}_{4}^{5-}\right)$ and silica $\left(\mathrm{SiO}_{4}^{4-}\right)$ that make up its primary cage structure [1] [2]. They exhibit a three-dimensional crystal structure consisting of aluminum, oxygen, silicon, and alkali/alkaline-earth metals such as sodium, potassium, and magnesium. Additionally, water molecules are typically 
trapped between gaps within the zeolite structure [3]. Zeolites have an open, cage-like framework which enables them to trap other molecules inside it as part of a physical process known as adsorption [4]. Adsorption occurs when a thin layer of molecules (gas, liquid, or solid) adheres to the surface of the pores of the adsorbent material. Zeolites are often referred to as molecular sieves due to the various sizes of pores in them, which is why they are generally considered effective adsorbents [5]. These properties make zeolites an ideal candidate for multiple applications.

Acid treatments are known to de-aluminate (to remove aluminum from) the molecular framework of zeolites, which opens up void space within the framework of the particles-thus making them more microporous than their untreated counterpart [6] [7] [8]. The overall surface area and pore volume of porous materials treated with acid have been shown to increase as well, which shows promise for them to be used as sorbents in wastewater treatment [9]. The use of acid treatments on aluminosilicates has proven useful in industrial processes such as fluid catalytic cracking (FCC), and it has been shown that acid treatments improve the catalytic properties of aluminosilicate frameworks. acid treatment can sometimes decrease the crystallinity or overall structural integrity of the crystal structure of the porous materials, which can reduce the overall silica concentration as well [7].

There is very limited literature about coating and functionalization of silica-based material with carbon-based products. Carbon exists in a variety of crystalline forms, two of which are graphite and diamond. Graphite has threefold, or $\mathrm{sp}^{2}$ hybridized bonding, and diamond has fourfold, or $\mathrm{sp}^{3}$ hybridized bonding. Plasma-enhanced chemical vapor deposition (PECVD) [10] rf, and dc sputtering [11] are just a few of the techniques used to fabricate carbon films with varying degrees of $\mathrm{sp}^{3}$ bonding, allowing the properties of carbon to be engineered for a specific application. Carbon synthesis, namely microporous 3D graphene-like carbon, has been employed using a zeolite template where ethylene and acetylene are the main sources of carbon rather than pure graphite [8]. In this specific case, the 3D graphene network can be formed inside the zeolite framework whereas in our study we deposit carbon on the surface of the zeolite samples. Another publication has also cited those carbon-based materials have been deposited onto zeolite and amorphous silica by method of methane decomposition [9]. In that study, different types of carbon material such as multi-walled carbon nanotubes and graphene nanosheets were successfully deposited onto silica-supported materials with an active Ni component Ni/ZSM-5(25) (Nickel-Zeolite Socony Mobil-5) and Ni/ZSM-5(400). Poly(acrylonitrile) and poly (furfuryl alcohol) were carbonized within zeolite nanochannels and then extracted after an acid treatment was done according to the researchers at Tohoku University in Japan [10]. The same group also successfully extracted pyrolytic carbon by exposing the zeolite to propylene at very high temperatures. 
In this work, carbon coated natural zeolite was fabricated by a novel method of deposition of carbon films by e-beam evaporation of graphite followed by acid treatment of the porous material. This study focuses on fabrication and characterization of the new material, and not on applications. Properties of the coated material were evaluated by gas sorption analysis, Fourier transform infrared spectroscopy (FTIR), Raman Spectroscopy, Scanning Electron Microscope (SEM), Energy Dispersive X-Ray Spectroscopy (EDS), and Thermal Gravimetrical Analysis (TGA).

\section{Experimental}

Australian natural clinoptilolite zeolite (diameter: 0.7 - $1 \mathrm{~mm}$, chemical composition: $68.26 \% \mathrm{SiO}_{2}, 12.99 \% \mathrm{Al}_{2} \mathrm{O}_{3}, 4.11 \% \mathrm{~K}_{2} \mathrm{O}, 2.09 \% \mathrm{CaO}, 1.37 \% \mathrm{Fe}_{2} \mathrm{O}_{3}, 0.83 \%$ $\mathrm{MgO}, 0.64 \% \mathrm{Na}_{2} \mathrm{O}, 0.23 \% \mathrm{TiO}_{2}$ ) was provided by Zeolite Australia Ltd. Carbon graphite pieces (99.99\%) and polyimide Kapton tape 2 inches diameter were purchased from Kurt J. Lesker Company (Clairton, PA). Electron-beam graphite evaporation was performed on a Lab 18 thin-film deposition system, Kurt J. Lesker Company (Clairton, PA).

Zeolite was cleaned following the method published elsewhere [12]. The zeolite particles were aligned on a piece of Kapton tape 2 inches $(5.08 \mathrm{~cm})$ in diameter. This choice was purely based on the amount of particles which could be placed on a single piece for each deposition process. A large diameter film can hold more zeolite particles thus requiring less trials to obtain a large enough sample for analyses. The Kapton tape was cut at roughly 6 inches $(15.24 \mathrm{~cm})$ in length and folded over so that each side had the adhesive exposed. The particles were simply poured over the surface of one side of the tape and spread uniformly to ensure only one layer of particles was present. After the deposition process, another piece of double-sided tape was pressed firmly against the recently coated zeolites. This ensured that the other side of the zeolite particles could now be exposed for the final deposition (Figure 1).

The thickness of the graphite being deposited was recorded by the crystal sensors inside the vacuum chamber. The density and z-ratio of carbon graphite were entered into the eKplise software to calculate it correctly. The rate and accumulated thickness were both monitored using the crystal which is located above and to the right of the electron beam crucible.

Approximately $10 \mathrm{mg}$ of dry powder sample was pulverized in a mortar and pestle. All IR spectra were recorded at room temperature $\left(21^{\circ} \mathrm{C} \pm 1^{\circ} \mathrm{C}\right)$ in the mid infrared range $\left(4000-150 \mathrm{~cm}^{-1}\right)$ using Shimadzu IR Tracer-100. Attenuated total reflection (ATR) is a method that allows the direct measurement of powder samples. ATR method involves pressing the sample against a high-refractive-index prism and measuring the infrared spectrum using infrared light that is totally internally reflected in the prism. Typically, 50 scans were signal-averaged for a single spectrum. Each spectrum is displayed in terms of absorbance as calculated from the reflectance-absorbance spectrum using the Lab 


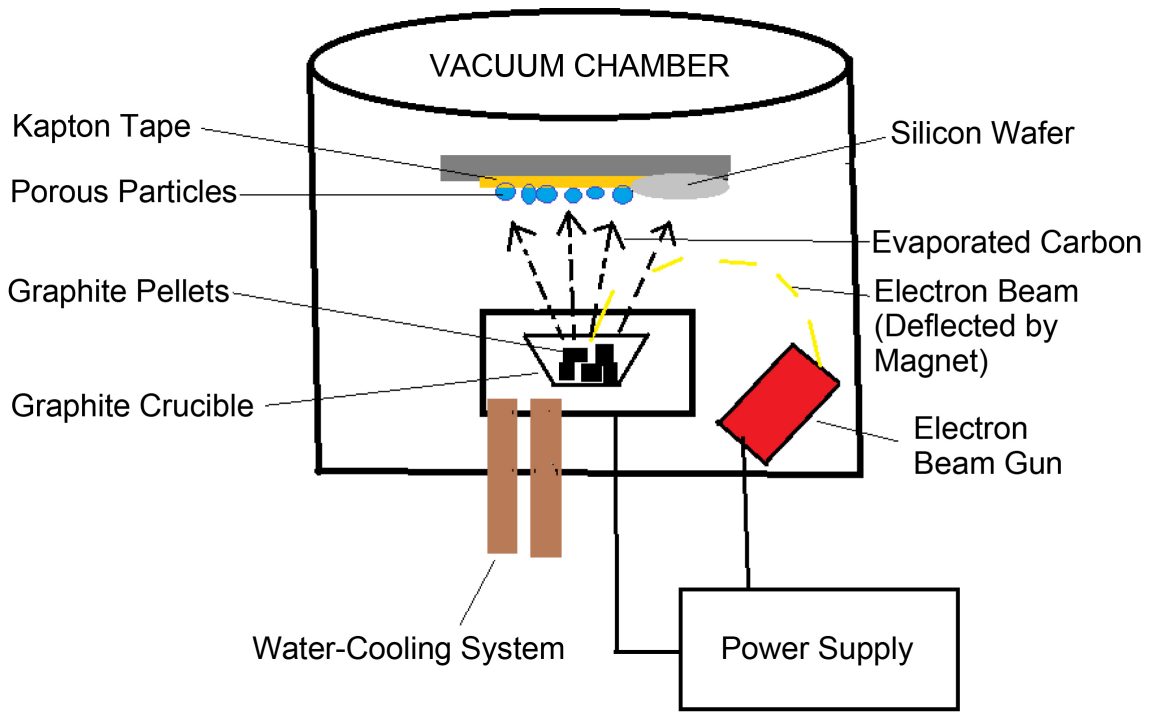

Figure 1. Schematic diagram of electro evaporation of graphite onto the zeolite particles and silicon wafer.

Solutions IR software. To minimize the difficulties arising from unavoidable shifts, baseline correction was applied. Each spectrum was normalized as normalization produces a spectrum in which maximum value of absorbance becomes 2 and minimum value 0 . To improve the resolution of complex bands, the digitized original spectrum was smoothed on noisy spectrum using Kubelka Munk algorithm and converted into its second derivative using the Savitzky-Golay algorithm [13] using 30-point smoothing. Raman spectra were taken using a Raman spectrometer with a $633 \mathrm{~nm}$ laser excitation (Renishaw 1000B).

The surface area, pore size and total pore volume distribution were determined by $\mathrm{N}_{2}$ adsorption isotherm, with relationship between the volume of nitrogen adsorbed at standard conditions $(\mathrm{V})$ and the partial pressure $(\mathrm{p} / \mathrm{p} 0)$ at 77 K (Autosorb IQ2, Quantachrome Instruments). Before analysis, samples were pretreated by degassing at $350^{\circ} \mathrm{C}$ for $12 \mathrm{~h}$, to remove any adsorbed species, and ensure pores are void of all other gasses before analysis. Additionally, before analysis a "secondary" degassing was performed, utilizing the Autosorb IQ2's "manual mode" function, for 15 minutes in the analysis station, using a combination of fine and course vacuum pumps. The pore size distributions were obtained by using the de-Boer V-T method and the Barrett-Joyner-Halenda (BJH) method. Surface are calculations which were made using the Non-Linear Density Functional theory (NLDFT, a modified version of Brunauer-Emmett-Teller (BET) suited for microporous samples and BET equation, a common method of surface area analysis. The morphology and composition of the zeolite particles were characterized using a Hitachi S-4800 field emission scanning electron microscope (FESEM). Samples were mounted on a carbon tape and coated with sputter with a conductive $2 \mathrm{~nm}$ iridium on SEM stubs and viewed at an accelerating voltage of 15.0 $\mathrm{kV}$. The chemical composition of the treated zeolite was determined by an energy dispersed spectroscopy (EDS) coupled to FESEM. 
Thermogravimetric Analysis (TGA) was carried out using a Shimadzu DTG-60AH with a heating rate of $5^{\circ} \mathrm{C} \cdot \mathrm{min}^{-1}$ in air atmosphere. The zeolite samples were added to a platinum pan filled to roughly one-fourth of the pan height. A reference platinum pan was used with no sample added to it during the analysis.

\section{Results and Discussion}

Raman and IR spectroscopy are techniques widely used to characterize zeolite samples based on their unique structural framework. Information such as the zeolite framework, cation locations, and adsorption and catalytic reactions have been explored extensively using these characterization methods [14]. Raman spectra of carbons (Figure 2) show several unique features in the $800-2000$ $\mathrm{cm}^{-1}$ range. The regions in which we are most concerned are the $\mathrm{D}$ and $\mathrm{G}$ peaks which lie around 1350 (D) and $1600 \mathrm{~cm}^{-1}$ (G) [15]. The D peak is due to the breathing modes of $\mathrm{sp}^{2}$ bonding in rings while the $\mathrm{G}$ peak is due to the bond stretching of all pairs of $\mathrm{sp}^{2}$ bonding within both rings and chains of carbon [15]. The graphite before being exposed to the electron beam shows peaks for the $D$ and $G$ bands, respectively, with an intensity ratio (D/G) of approximately 0.84533. Interestingly, the graphite after the electron beam exposure has a $\mathrm{D}$ band that shows a much lower intensity, and this graphite sample had an intensity ratio $(\mathrm{D} / \mathrm{G})$ of 0.5299 . The decrease in intensity is indicative of decreased $\mathrm{sp}^{2}$ bonding in the carbon rings, moving towards a more disordered carbon network [16]. This ratio implies that the electron beam has altered the $\mathrm{D}$ band structure in the graphite, but the $\mathrm{G}$ band remains relatively the same. The porous particles

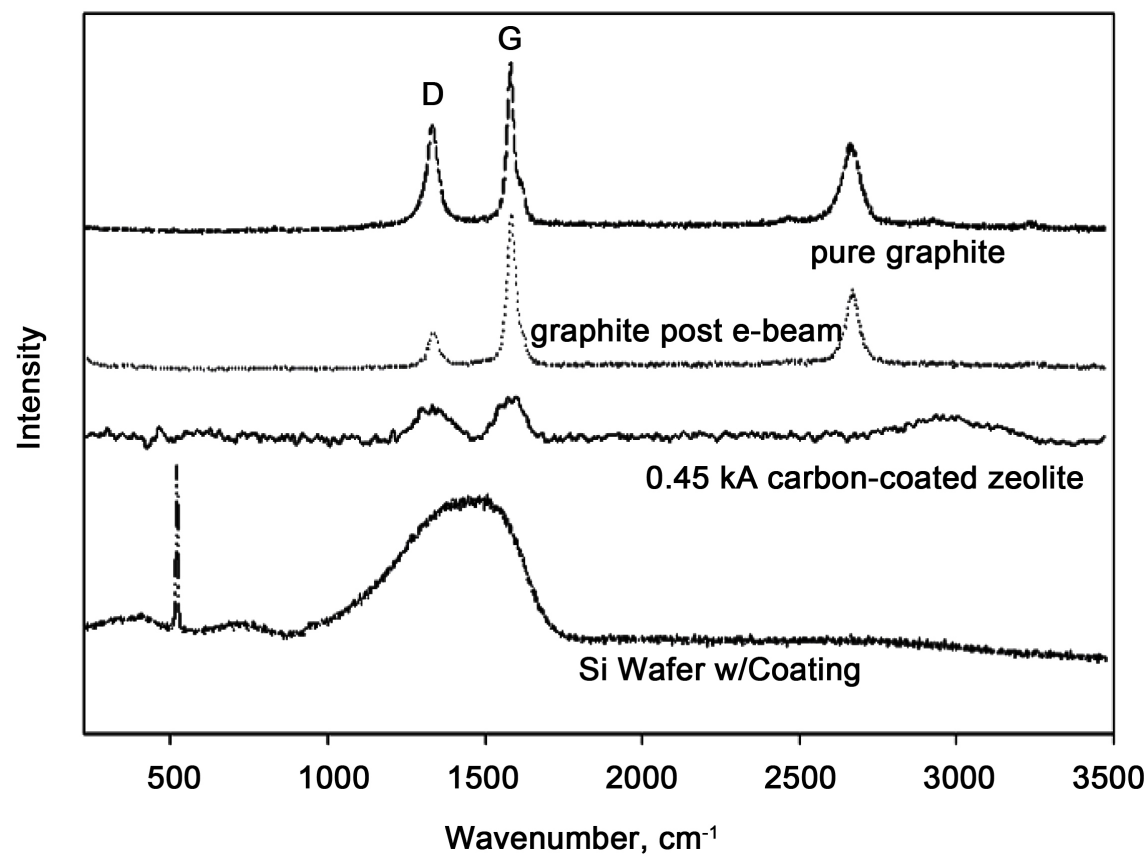

Figure 2. Raman spectroscopy (top to bottom) of pure graphite, graphite after e-beam exposure, carbon-coated zeolite, and silicon wafer with carbon coating. 
with a $0.45 \mathrm{k} \AA$ coating show intensities for both the D and G bands, however, the $\mathrm{D} / \mathrm{G}$ ratio is 0.8899 . The broadness and less intense peaks of the Raman spectra of the coated particles compared to pure graphite indicates that bonding disorder is occurring after electron beam exposure. According to Ferrari, bonding disorder of carbon can be characterized by $\mathrm{G}$ and $\mathrm{D}$ peak dispersion where the dispersion is proportional to the degree of disorder [17]. A silicon wafer was placed onto the substrate platen next to the zeolite particles during the deposition process. The Raman spectra for the silicon wafer show only one broad peak in between the $\mathrm{D}$ and $\mathrm{G}$ band peaks of the aforementioned graphite samples. This large, broad peak was not expected from the wafer but more or less confirms the deposition of a highly disordered carbon film on the surface that exhibits a "hybrid" of bonding between the G and D peaks [18]. Such a broad distribution between the $G$ and $D$ peak location confirms the disordered structure of amorphous carbon that is on the surface of the wafer.

Vibrational spectroscopies have been one of the most widely used methods to characterize the structure of zeolites as well as their changes in structure during synthesis and usage [19]. The focus is on the vibrational modes such as the bending and stretching frequencies that are seen in these porous particles. The zeolite framework is composed of a tetrahedral network composed of $\mathrm{TO}_{4}(\mathrm{~T}$ denotes $\mathrm{Al}$ or $\mathrm{Si}$ ) that give rise to typical bands in the mid-IR and far-IR regions [3]. The silica bending peaks, O-Si-O, around $1050-1051 \mathrm{~cm}^{-1}$, are the most notable difference one can see from the FTIR curve (Figure 3(a)) [20]. The 0.45 $\mathrm{k} \AA$ carbon-coated porous particles have much more intense silica peaks which suggests that the coating on these particles is raising the overall prominence of silica within the molecular framework of the material. The acid treated particles, on the other hand, have the lowest intensity peaks for the silica bending band. When zeolites are treated with acid, they can be de-aluminated. This means that the acid treatment removes a significant amount of aluminum from the zeolite framework and thus disrupts the alumina $\left(\mathrm{AlO}_{4}^{-}\right)$tetrahedral framework within the particles [6] [9]. The alumina peak (Al-OH) at $3630 \mathrm{~cm}^{-1}$ can be seen at its highest intensity within the clean porous particles and almost non-existent for the acid-treated particles (Figure 3(b)) The coated zeolite have a less intense peak at $3630 \mathrm{~cm}^{-1}$, but clearly not as small of a peak as the acid-treated particles. The acid treatment seems to be effective in de-aluminating the porous materials. The carbon-coating seems to have restored some of the structural $\mathrm{Si}$ and $\mathrm{Al}$ of the samples that was lost with the acid treatment, which may explain why the $\mathrm{Si}$ and $\mathrm{Al}$ peaks were both larger afterwards. This re-alumination, in addition to inserting Si back into the framework, peaks the coatings ability to restore the crystallinity of the sample.

Using the BET model via nitrogen adsorption at $77 \mathrm{~K}$ is an effective way of determining surface area of a porous material. However, it is generally accepted that the BET equation is not suitable for microporous materials [21]. The Non Local Density Functional Theory (NLDFT) equation, a modified BET model, is 


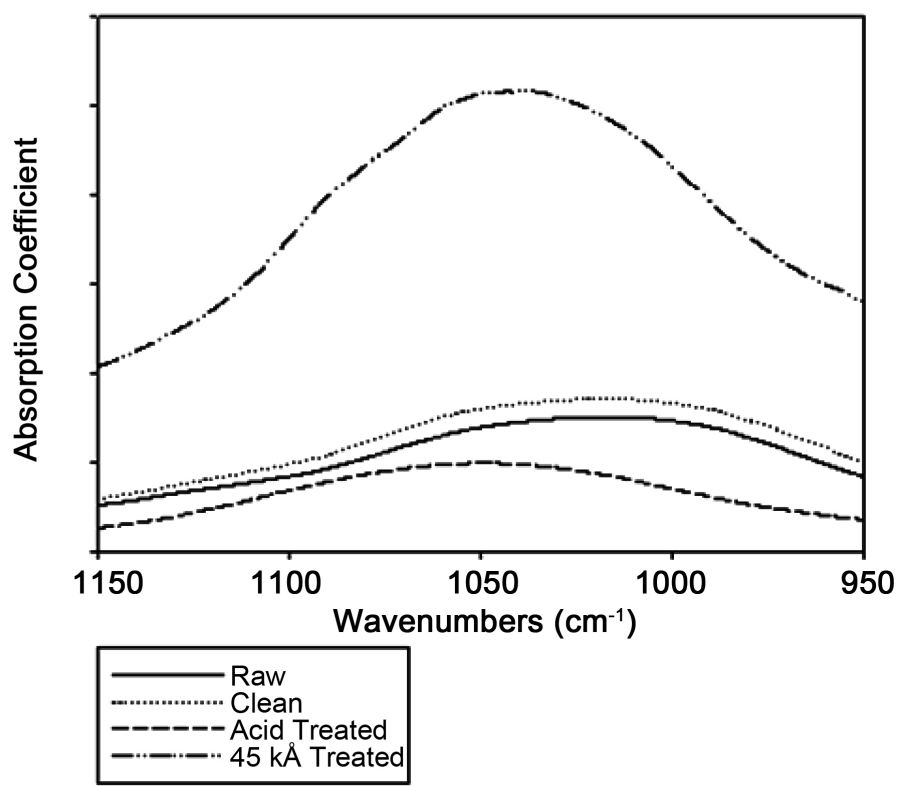

(a)

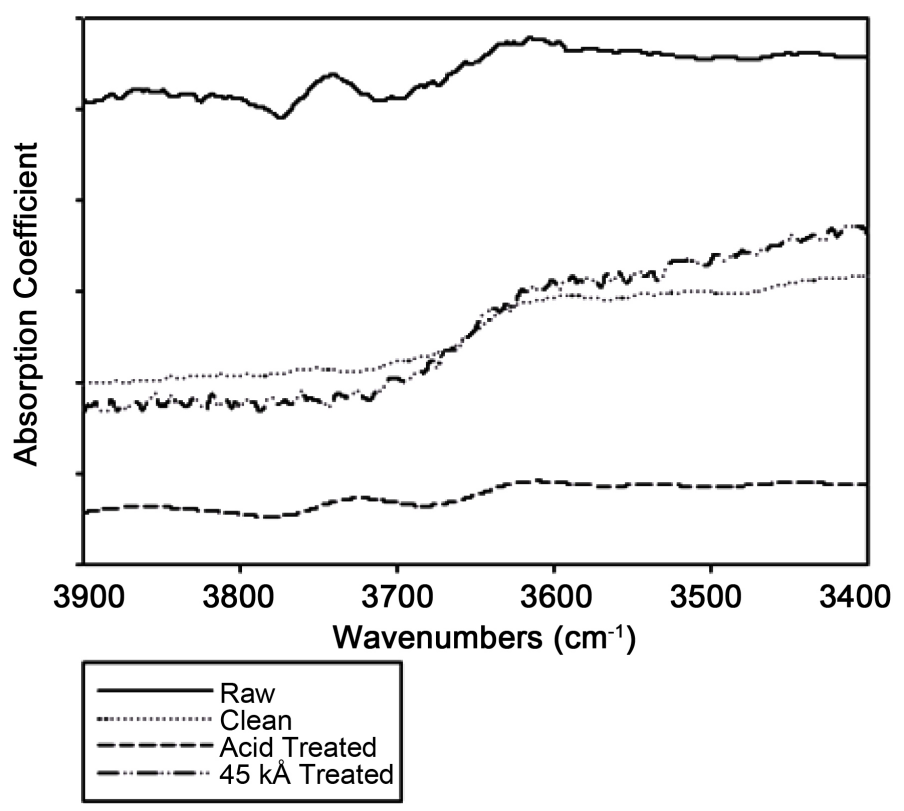

(b)

Figure 3. FTIR plots. (a) Silica peak at $1050-1040 \mathrm{~cm}^{-1}$. The $0.45 \AA$ carbon-coated particle has the highest and most intense peak when compared to the other samples. (b) Alumina peak at $3610 \mathrm{~cm}^{-1}$. The raw particle has the highest peak position, while the acid treated particle has the lowest and least intense. The clean and $0.45 \mathrm{k} \AA$ carbon-coated particle have nearly identical peak positions.

suited for microporous materials, and is the method used in this study to calculate the pore size and surface area of the material [22]. Table 1 shows properties of zeolite that determine its adsorption capacity: pore diameter, pore volume, and overall adsorption surface area. 
Table 1. Surface area, pore volume, and average pore width of each zeolite specimen.

\begin{tabular}{cccc}
\hline Zeolite & $\begin{array}{c}\text { Surface Area } \\
\left(\mathrm{m}^{2} \cdot \mathrm{g}^{-1}\right)\end{array}$ & $\begin{array}{c}\text { Pore Volume } \\
\left(\mathrm{cm}^{3} \cdot \mathrm{g}^{-1}\right)\end{array}$ & $\begin{array}{c}\text { Average Pore } \\
\text { Width }(\AA)\end{array}$ \\
\hline Raw zeolite & 10.39 & 0.005 & 7.16 \\
Clean zeolite & 15.15 & 0.034 & 10.24 \\
$\mathrm{H}_{2} \mathrm{SO}_{4}$ treated & 108.50 & 0.032 & 5.31 \\
Carbon coated zeolite & 160.05 & 0.044 & 5.31 \\
\hline
\end{tabular}

The carbon coating on the zeolite surface appears to have increased the surface area of the material in its natural state more than tenfold (from 10.38 to $\left.160.05 \mathrm{~m}^{2} \cdot \mathrm{g}^{-1}\right)$. Other studies report having similar metal organic frameworks that often have surface areas exceeding $500 \mathrm{~m}^{2} \cdot \mathrm{g}^{-1}$ [23] [24]. Additionally, these particles come nowhere near the surface area of ordinary activated carbon frameworks, which can be near $2000 \mathrm{~m}^{2} \cdot \mathrm{g}^{-1}$ as reported in some studies [25]. Pore volume also increased from 0.00557 to $0.0446 \mathrm{~cm}^{3} \cdot \mathrm{g}^{-1}$, which is a large increase by almost a factor of 10 . The average pore radius decreased from 7.16 to $5.305 \AA$, which indicates that the treatment was effective in opening incredibly small void spaces commonly referred to as micropores in the framework. This would explain why the average pore radius decreased, but the overall pore volume increased drastically [26]. This agrees with comparison of isotherms of both raw particles and coated particles (Figure 4). The almost vertical portion of the curve for the coated material extends up to about $25 \mathrm{~cm}^{3}$, indicating more volume is being accounted for by micro pores in this sample, which fill at lower pressures.

Enhanced adsorption properties are evidenced by SEM image (Figure 5), which depicts typical elongated features of zeolite and smaller particles, which are the result of the acid treatment and carbon coating. In addition, SEM images suggest that particles are homogeneously coated as dark areas can be consistently observed.

EDS data (summarized in Table 2) quantifies the impact the treatments have on the overall $\mathrm{Si}$ and $\mathrm{Al}$ concentrations of the raw material, clean material, $\mathrm{H}_{2} \mathrm{SO}_{4}$ treated, and carbon-coated zeolite samples. The mass percentage and atomic percentage of each constituent of the zeolite can be determined. In this case, we are primarily concerned with the $\mathrm{Si} / \mathrm{Al}$ ratio of each sample, which increase after the e-beam coating.

The acid treatment produced the highest overall $\mathrm{Si} / \mathrm{Al}$ ratio and had the lowest $\mathrm{Al} \%$ by mass. These results support the theory that the acid treatment should dealuminate the zeolite. The carbon coated material re-aluminated the sample and brought the $\mathrm{Si} / \mathrm{Al}$ ratio close to what it was for the raw material $(3.95 \mathrm{Si} / \mathrm{Al}$ originally to $4.12 \mathrm{Si} / \mathrm{Al}$ with the carbon coated sample). Additionally, the individual Si \% and $\mathrm{Al} \%$ returned to similar percentages compared to the raw material. 


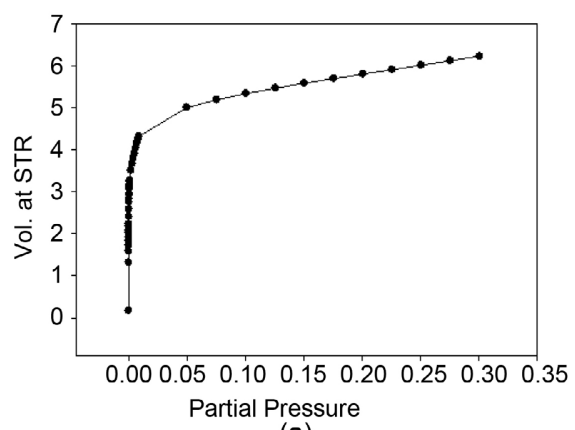

(a)

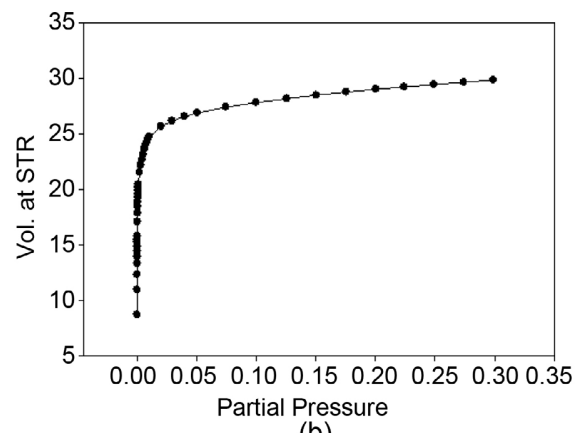

(b)

Figure 4. Isotherm of raw material (a) and coated material (b). Notice how the almost vertical portion of the curve for the coated material extends up to about $25 \mathrm{~cm}^{3}$, indicating more volume is being accounted for by micro pores in this sample, which fill at lower pressures.

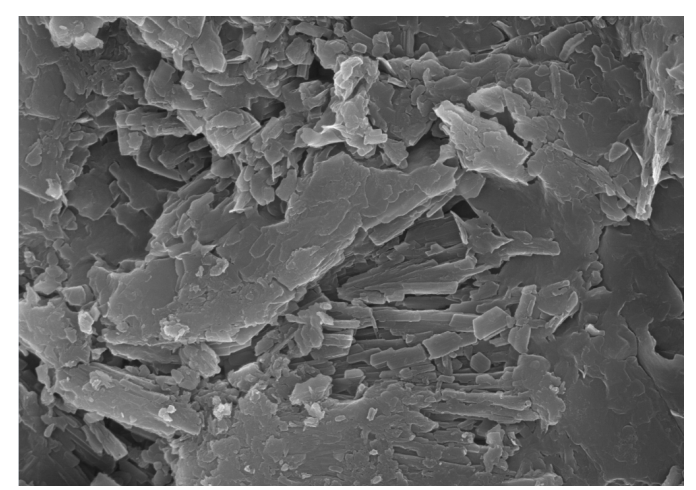

Figure 5. SEM images of the e-beam treated particles at $20 \times$ magnification.

Table 2. Atomic $\%$ and weight $\%$ of $\mathrm{Al}$ and $\mathrm{Si}$ for each sample. The graphene sputtering not only restored the $\mathrm{Si} / \mathrm{Al}$ ratio of the clean material but increased it to from 12.803 to 13.685 .

\begin{tabular}{cccccc}
\hline Zeolite & $\begin{array}{c}\mathrm{Al} \\
\text { atomic } \%\end{array}$ & $\begin{array}{c}\mathrm{Al} \\
\text { weight } \%\end{array}$ & $\begin{array}{c}\mathrm{Si} \\
\text { atomic } \%\end{array}$ & $\begin{array}{c}\mathrm{Si} \\
\text { weight } \%\end{array}$ & $\begin{array}{c}\text { Si/Al mass } \\
\text { ratio }\end{array}$ \\
\hline Raw Zeolite & 5.38 & 7.65 & 21.17 & 30.23 & 3.95 \\
Clean Zeolite & 1.85 & 2.59 & 22.80 & 33.16 & 12.80 \\
Acid Treated & 1.18 & 1.78 & 15.52 & 24.36 & 13.69 \\
Carbon coated zeolite & 5.18 & 7.31 & 20.51 & 30.13 & 4.12 \\
\hline
\end{tabular}

Thermal analyses were performed on the carbon-coated zeolite sample and compared alongside a clean and acid-treated zeolite sample for reference. The TGA curves for each sample (Figure 6) are very similar which suggests that the thermal properties between them are somewhat related depending on the temperature range.

The carbon-coated zeolite exhibits a smaller weight loss at temperatures greater than $250^{\circ} \mathrm{C}$ compared to the acid-treated and clean zeolite samples. Each zeolite sample shows a large drop in weight loss percentage at temperatures up 


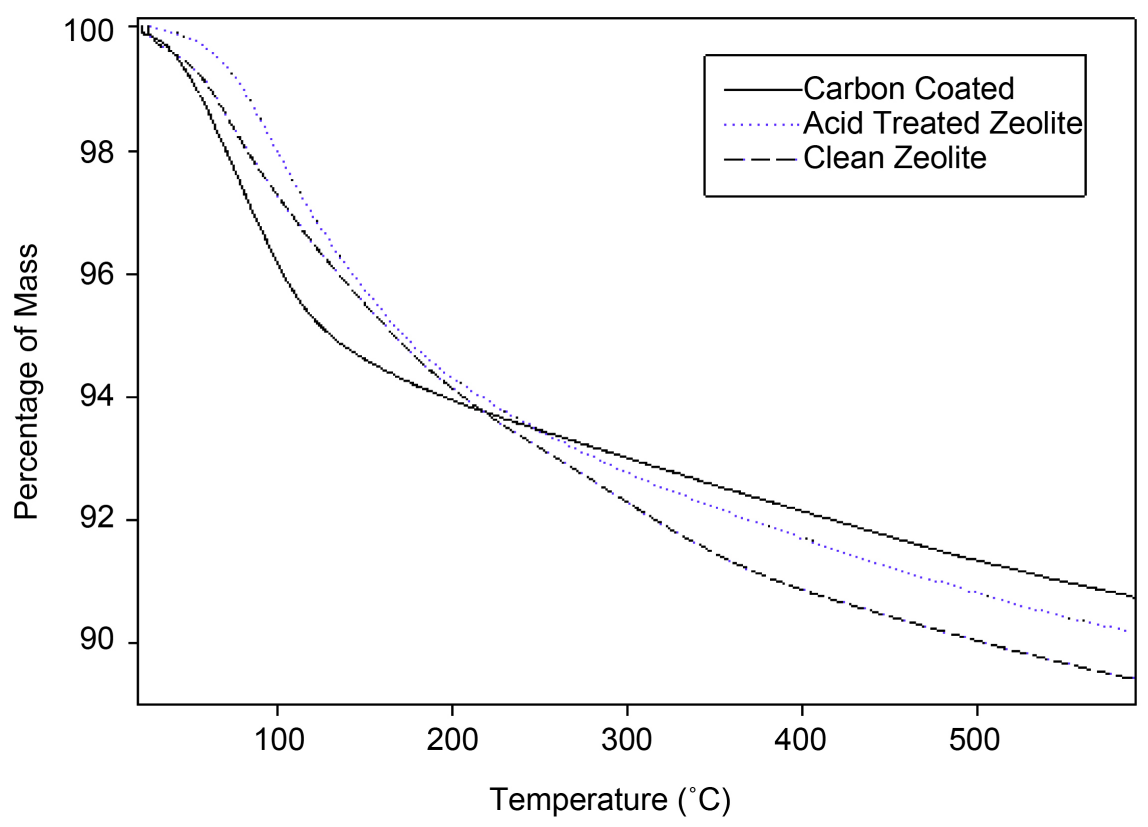

Figure 6. TGA plot of carbon coated, clean, and acid-treated zeolite.

to $150^{\circ} \mathrm{C}-175^{\circ} \mathrm{C}$ which is most likely due to the desorption of free water molecules trapped inside the pores of the zeolite framework. The carbon-coated zeolite lost $5.75 \%$ mass while the clean and acid-treated samples lost $5.25 \%$ and $5.09 \%$ from room temperature up to $175^{\circ} \mathrm{C}$. At $500^{\circ} \mathrm{C}$, the carbon-coated zeolite loses $8.65 \%$ of its initial weight while the clean and acid-treated samples lose $9.96 \%$ and $9.18 \%$.

This shows that the carbon-coated zeolite samples are slightly more thermally stable at higher temperatures when compared to the clean and acid-treated zeolites but not by much. A similar study including TGA analysis on zeolite/carbon activated composites by Lakhera [27] shows a similar decrease in weight at around $10 \%-13 \%$ between this temperature range. A study was done by Masika and Mokaya [28] where TGA was performed on zeolite-templated carbons showed a decrease in percent weight loss between $23 \%-90 \%$ but at higher temperatures greater than $400^{\circ} \mathrm{C}$. Between the temperature range of $400^{\circ} \mathrm{C}-550^{\circ} \mathrm{C}$ it appears the weight loss is attributable to the combustion of the carbon component associated with the zeolite framework.

This study focuses on the fabrication of the new material and characterization and not on applications. Even though financial analysis has not been performed, we expect the cost of the material to be high considering the sophisticated deposition utilized in the fabrication process. Given the properties of the new material we expect it to be suitable for sensors and specialized filtration materials. Future work includes investigation of potential industrial applications of these treatments and its commercial viability.

\section{Conclusion}

FTIR results showed that the raw material does in fact have a higher concentra- 
tion of $\mathrm{Al}$ bonds within the framework and that the acid treatment is effective in dealumination of these materials. In addition, FTIR profile was significantly more prominent on the e-beam treated particles, followed by clean, closely followed by raw, and the acid treated particle had the most diminished Si-O-Si peak. This implies that the sulfuric acid treatment not only significantly impacts the framework of the Al bonds, but also reduces the dominance of the Si bonds within the silica framework. The final e-beam treatment increased the overall adsorption surface area from 10.386 , to $160.05 \mathrm{~m}^{2} \cdot \mathrm{g}^{-1}$, more than a tenfold increase. The reduction in D/G band intensity and increased D/G peak broadness from pure graphite compared to the coated zeolite specimens is evidence that there is a degree of carbon bonding disorder occurring during the deposition process. The carbon-coating not only restores this crystallinity, but re aluminates the zeolite, and brings the $\mathrm{Si} / \mathrm{Al}$ ratio close to what it was for the raw material. The carbon coating also restores the bulk of the inter framework Si that was present in the raw material. Future work includes investigation of industrial application of the new material and its commercial viability.

\section{Acknowledgements}

Authors would like to thank Yan Zhang for assisting with SEM analysis, Steve Hardcastle for the use of the Raman microscope in the Advanced Analytical Facility (AAF), and Heather Owen for the use of the UWM Electron Microscope Laboratory. This project was funded by UWM Support for Undergraduate Research Fellows (SURF) grant to Andrew Morgan and Joseph Corrao.

\section{Conflicts of Interest}

The authors declare no conflicts of interest regarding the publication of this paper.

\section{References}

[1] Cejka, J., van Bekkum, H., Corma, A. and Schueth, F. (2007) Introduction to Zeolite Science and Practice. Elsevier, Amsterdam, 1000.

[2] Jha, B. and Singh, D.N. (2016) Fly Ash Zeolites: Innovations, Applications, and Directions. Springer, Berlin. https://doi.org/10.1007/978-981-10-1404-8

[3] Baerlocher, Ch., McCusker, L.B. and Olson, D.H. (2007) Atlas of Zeolite Framework types. Elsevier, Amsterdam, 3-11. https://doi.org/10.1016/B978-044453064-6/50187-0

[4] Wang, S. and Peng, Y. (2009) Natural Zeolites as Effective Adsorbents in Water and Wastewater Treatment. Chemical Engineering Journal, 156, 11-24. https://doi.org/10.1016/j.cej.2009.10.029

[5] Van Donk, S., Janssen, A.H., Bitter, J.H. and de Jong, K.P. (2007) Generation, Characterization, and Impact of Mesopores in Zeolite Catalysts. Catalysis Reviews, 45, 297-319. https://doi.org/10.1081/CR-120023908

[6] Apelian, M.R., Fung, A.S., Kennedy, G.J. and Degnan, T.F. (1996) Dealumination of Zeolite â via Dicarboxylic Acid Treatment. The Journal of Physical Chemistry, 100, 16577-16583. https://doi.org/10.1021/jp960376s 
[7] Pandaa, A.K., Mishraa, B.G., Mishrac, D.K. and Singha, R.K. (2010) Effect of Sulphuric Acid Treatment on the Physico-Chemical Characteristics of Kaolin Clay. Colloids and Surfaces A: Physiochemical Engineering Aspects, 363, 98-104. https://doi.org/10.1016/j.colsurfa.2010.04.022

[8] Silva, M., Lecus, A., Lin, Y. and Corrao, J. (2019) Tailoring Natural Zeolites by Acid Treatments. Journal of Materials Sciences and Chemical Engineering, 7, 26-37. https://doi.org/10.4236/msce.2019.72003

[9] Matias, P., Lopes, J.M., Ayrault, P., Laforge, S., Magnoux, P., Guisnet, M. and Ramôa Ribeiro, F. (2009) Effect of Dealumination by Acid Treatment of a HMCM-22 Zeolite on the Acidityand Activity of the Pore Systems. Applied Catalysis A: General, 365, 207-213. https://doi.org/10.1016/j.apcata.2009.06.014

[10] Endo, K. and Tatsumi, T. (1995) Fluorinated Amorphous Carbon Thin Films Grown by Plasma Enhanced Chemical Vapor Deposition for Low Dielectric Constant Interlayer Dielectrics. Journal of Applied Physics, 78, 1370-1372.

https://doi.org/10.1063/1.360313

[11] Schwan, J., Ulrich, S., Roth, H. and Ehrhardt, H. (1996) Tetrahedral Amorphous Carbon Films Prepared by Magnetron Sputtering and dc Ion Plating. Journal of Applied Physics, 79, 1416-1422. https://doi.org/10.1063/1.360979

[12] Silva, M.R., Lecus, A., Gajdardziska-Josifovska, M., Schofield, M., Virnoche, M., Chang, J., Chen, J. and Garman, D. (2020) Graphene-Oxide Loading on Natural Zeolite Particles for Enhancement of Adsorption Properties. RSC Advances, 10, 4589-4597. https://doi.org/10.1039/C9RA00572B

[13] Savitzky, A. and Golay, M.J.E. (1964) Smoothing and Differentiation of Data by Simplified Least Squares Procedures. Analytical Chemistry, 36, 1627-1639.

https://doi.org/10.1021/ac60214a047

[14] Li, C. and Wu, Z. (2003) Microporous Materials Characterized by Vibrational Spectroscopies. In: Auerbach, S.M., Carrado, K.A. and Dutta, P.K., Eds., Handbook of Zeolite Science and Technology, CRC Press, Boca Raton, 1204 p.

[15] Childres, I., Jauregui, L.A., Park, W., Cao, H. and Chen, Y.P. (2013) Raman Spectroscopy of Graphene and Related Materials. In: Jang, J.I., Ed., New Developments in Photon and Materials Research, NOVA Science Publishers, Inc., New York, 403-418.

[16] Bokobza, L., Bruneel, J.-L. and Couzi, M. (2014) Raman Spectroscopy as a Tool for the Analysis of Carbon-Based Materials (Highly Oriented Pyrolytic Graphite, Multilayer Graphene and Multiwall Carbon Nanotubes) and Some of Their Elastic Composites. Vibrational Spectroscopy, 74, 57-63.

https://doi.org/10.1016/j.vibspec.2014.07.009

[17] Ferrari, A.C. (2007) Raman Spectroscopy of Graphene and Graphite: Disorder, Electron-Phonon Coupling, Doping and Nonadiabatic Effects. Solid State Communications, 143, 47-57. https://doi.org/10.1016/j.ssc.2007.03.052

[18] Wu, H., Zhou, T., Zhang, N. and Zhu, X. (2017) Assessments of the Relation between the Degree of the Ultrafast Laser Deposited Carbon Film and the Features of the Raman Spectrum's D Band. Surface and Coatings Technology, 311, 55-62. https://doi.org/10.1016/j.surfcoat.2016.12.108

[19] Bhaskar, G.P. and Saikia, J. (2010) Fourier Transform Infrared Spectroscopic Characterization of Kaolinite from Assam and Meghalaya, Northeastern India. Journal of Modern Physics, 1, 206-210. https://doi.org/10.4236/jmp.2010.14031

[20] Tomozawa, M., Lee, Y.-K. and Peng, Y.-L. (1998) Effect of Uniaxial Stresses on Silica Glass Structure Investigated by IR Spectroscopy. Journal of Non-Crystalline Sol- 
ids, 242, 104-109. https://doi.org/10.1016/S0022-3093(98)00780-7

[21] Bae, Y.-S., Yazaydın, A.O. and Snurr, R.Q. (2010) Evaluation of the BET Method for Determining Surface Areas of MOFs and Zeolites that Contain Ultra-Micropores. Langmuir, 26, 5475-5483. https://doi.org/10.1021/la100449z

[22] Landers, J., Gor, G.Y. and Neimark, A.V. (2013) Density Functional Theory Methods for Characterization of Porous Materials. Colloids and Surfaces A: Physicochemical and Engineering Aspects, 473, 3-32. https://doi.org/10.1016/j.colsurfa.2013.01.007

[23] Park, K.S., Ni, Z., Côté, A.P., Choi, J.Y., Huang, R., Uribe-Romo, F.J., Chae, H.K., O'Keeffe, M. and Yaghi, O.M. (2006) Exceptional Chemical and Thermal Stability of Zeolitic Imidazolate Frameworks. Proceedings of the National Academy of Sciences of the United States of America, 103, 10186-10191.

https://doi.org/10.1073/pnas.0602439103

[24] Xin, F., Yuan, Z.X., Wang, W.C. and Du, C.X. (2017) Experimental Comparison of Adsorption Characteristics of Silica Gel and Zeolite in Moist Air. Heat Mass Transfer, 53, 387-394. https://doi.org/10.1007/s00231-016-1829-y

[25] Tan, I.A.W., Ahmad, A.L. and Hameed, B.H. (2008) Adsorption of Basic Dye on High-Surface-Area Activated Carbon Prepared from Coconut Husk: Equilibrium, Kinetic and Thermodynamic Studies. Journal of Hazardous Materials, 154, 337-346. https://doi.org/10.1016/j.jhazmat.2007.10.031

[26] Mikhail, R.S., Brunauer, S. and Bodor, E.E. (1968) Investigations of a Complete Pore Structure Analysis. Journal of Colloid and Interface Science, 26, 45-53. https://doi.org/10.1016/0021-9797(68)90270-1

[27] Lakhera, S.K., Sree, H.A. and Suman, S. (2015) Synthesis and Characterization of 13X Zeolite/Activated Carbon Composite. International Journal of ChemTech Research, 7, 1364-1368.

[28] Masika, E. and Mokaya, R. (2013) Preparation of Ultrahigh Surface Area Porous Carbons Templated Using Zeolite 13X for Enhanced Hydrogen Storage. Progress in Natural Science: Materials International, 23, 308-316.

https://doi.org/10.1016/j.pnsc.2013.04.007 